\title{
SSD1 modifies phenotypes of Elongator mutants
}

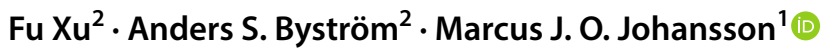

Received: 20 October 2019 / Revised: 19 November 2019 / Accepted: 20 November 2019 / Published online: 27 November 2019 (c) The Author(s) 2019

\begin{abstract}
The translational decoding properties of tRNAs are influenced by post-transcriptional modification of nucleosides in their anticodon region. The Elongator complex promotes the first step in the formation of 5-methoxycarbonylmethyl $\left(\mathrm{mcm}^{5}\right)$, 5-methoxycarbonylhydroxymethyl $\left(\mathrm{mchm}^{5}\right)$, and 5-carbamoylmethyl $\left(\mathrm{ncm}^{5}\right)$ groups on wobble uridine residues in eukaryotic cytosolic tRNAs. Elongator mutants in yeast, worms, plants, mice, and humans not only show a tRNA modification defect, but also a diverse range of additional phenotypes. Even though the phenotypes are almost certainly caused by the reduced functionality of the hypomodified tRNAs in translation, the basis for specific phenotypes is not well understood. Here, we discuss the recent finding that the phenotypes of Saccharomyces cerevisiae Elongator mutants are modulated by the genetic background. This background-effect is largely due to the allelic variation at the SSDI locus, which encodes an mRNA-binding protein involved in post-transcriptional regulation of gene expression. A nonsense $s s d l$ allele is found in several wild-type laboratory strains and the presence of this allele aggravates the stress-induced phenotypes of Elongator mutants. Moreover, other phenotypes, such as the histone acetylation and telomeric gene silencing defects, are dependent on the mutant ssdl allele. Thus, SSD1 is a genetic modifier of the phenotypes of Elongator-deficient yeast cells.
\end{abstract}

Keywords Elongator complex $\cdot$ tRNA modification $\cdot$ Translation $\cdot$ mRNA-binding protein

\section{Introduction}

Post-transcriptionally modified nucleosides are found within all tRNA molecules. Modified nucleosides in the anticodon region usually promote proper anticodon-codon interactions and they are consequently important for the efficiency and fidelity of translation (Agris et al. 2017; Björk and Hagervall 2014). Uridine residues present at the wobble position (nucleoside 34) in eukaryotic cytosolic tRNAs are frequently modified to an $\mathrm{xm}^{5} \mathrm{U}$-type of modified nucleoside where the $\mathrm{xm}^{5}$ moiety is either a 5-methoxycarbonylmethyl $\left(\mathrm{mcm}^{5}\right), 5$-methoxycarbonylhydroxymethyl $\left(\mathrm{mchm}^{5}\right)$, or 5-carbamoylmethyl $\left(\mathrm{ncm}^{5}\right)$ group (Machnicka et al. 2014). The $\mathrm{xm}^{5} \mathrm{U}$ residues sometimes also contain an additional

Communicated by M. Kupiec.

Marcus J. O. Johansson

marcus.johansson@umu.se

1 Västerbotten County Council/Department of Odontology, Umeå University, 90187 Umeå, Sweden

2 Department of Molecular Biology, Umeå University, 90187 Umeå, Sweden
2'-O-methyl $\left(\mathrm{xm}^{5} \mathrm{Um}\right)$ or 2-thio $\left(\mathrm{xm}^{5} \mathrm{~s}^{2} \mathrm{U}\right)$ group. The presence of an $\mathrm{xm}^{5} \mathrm{U}_{34}, \mathrm{xm}^{5} \mathrm{Um}_{34}$, or $\mathrm{xm}^{5} \mathrm{~s}^{2} \mathrm{U}_{34}$ residue is generally believed to improve pairing with the cognate codon(s) (Agris et al. 2017; Björk and Hagervall 2014; Björk et al. 2007; Johansson et al. 2008; Lim 1994). In this review, we discuss the phenotypic consequences of the lack of wobble $\mathrm{xm}^{5}$ groups in Saccharomyces cerevisiae, focusing on the recent finding that the phenotypes are modulated by the genetic background.

The first step in formation of the $\mathrm{xm}^{5}$ groups is dependent on the Elongator complex, which is composed of two sets of the six Elp proteins (Elp1-Elp6) (Dauden et al. 2017, 2018; Huang et al. 2005; Johansson et al. 2018; Kolaj-Robin and Seraphin 2017; Setiaputra et al. 2017; Winkler et al. 2001). Elongator is thought to catalyze the formation of a $\mathrm{cm}^{5} \mathrm{U}_{34}$ residue, which is then further modified by additional enzymes. The $\mathrm{xm}^{5}$ moiety found in cytosolic $S$. cerevisiae tRNAs is either an $\mathrm{mcm}^{5}$ or $\mathrm{ncm}^{5}$ group. Such groups are present in $11 \mathrm{U}_{34}$-containing tRNA species of which two carry $\mathrm{mcm}^{5} \mathrm{U}_{34}$, three $\mathrm{mcm}^{5} \mathrm{~s}^{2} \mathrm{U}_{34}$, five $\mathrm{ncm}^{5} \mathrm{U}_{34}$, and one $\mathrm{ncm}^{5} \mathrm{Um}_{34}$ (Fig. 1) (Johansson et al. 2008 and references therein). In addition to the lack of $\mathrm{mcm}^{5} / \mathrm{ncm}^{5}$ groups in the 11 tRNAs (Huang et al. 2005; Johansson et al. 2008), 

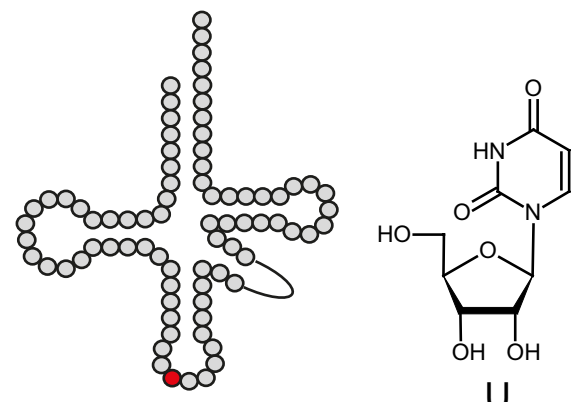

$U$
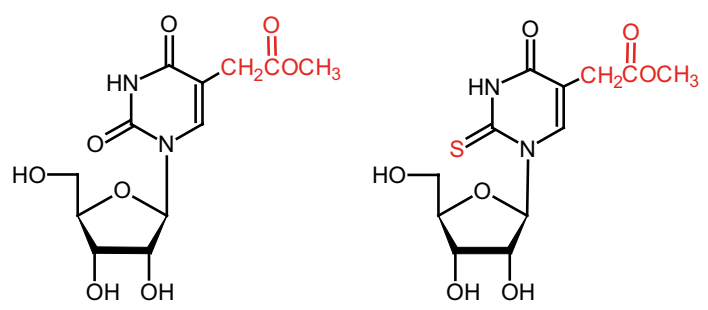

$\mathrm{mcm}^{5} \mathrm{U}$

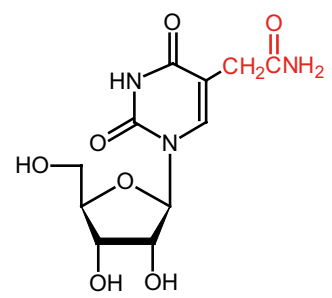

$\mathrm{ncm}^{5} \mathrm{U}$

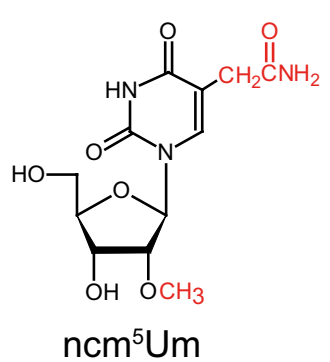

$\mathrm{ncm}{ }^{5} \mathrm{Um}$

Fig. 1 Schematic secondary tRNA structure and the chemical structures of $\mathrm{U}, \mathrm{mcm}^{5} \mathrm{U}, \mathrm{mcm}^{5} \mathrm{~s}^{2} \mathrm{U}, \mathrm{ncm}^{5} \mathrm{U}$, and $\mathrm{ncm}^{5} \mathrm{Um}$. The wobble position and posttranscriptional modifications are indicated in red

the inactivation of yeast Elongator leads to a wide range of phenotypes. These phenotypes include slow growth as well as increased sensitivity to various stress-inducing substances and conditions (Frohloff et al. 2001; Karlsborn et al. 2014; Otero et al. 1999). Moreover, Elongator mutants have been reported to show defects in histone acetylation, RNA polymerase II transcription, telomeric gene silencing, mitochondrial function, exocytosis, and protein homeostasis $(\mathrm{Li}$ et al. 2009b; Nedialkova and Leidel 2015; Otero et al. 1999; Rahl et al. 2005; Tigano et al. 2015; Winkler et al. 2002). All of these phenotypes, except for the tRNA modification defect, are suppressed by increased expression of various combinations of tRNA $\mathrm{UUU}_{\mathrm{UU}}^{\mathrm{Ly}}, \mathrm{tRNA}_{\mathrm{UUG}}^{\mathrm{Gln}}$, and tRNA $\mathrm{UUC}_{\mathrm{UU}}^{\mathrm{Glu}}$ which are the three $S$. cerevisiae tRNA species that normally carry a mcm ${ }^{5} \mathrm{~s}^{2} \mathrm{U}_{34}$ residue (Chen et al. 2011; Esberg et al. 2006; Nedialkova and Leidel 2015; Tigano et al. 2015). These findings indicate the lack of the $\mathrm{mcm}^{5} / \mathrm{ncm}^{5}$ groups preferentially affects the functionality of tRNA ${ }_{\mathrm{UUU}}^{\mathrm{Lys}}$, $\mathrm{RNA}_{\mathrm{UUG}}^{\mathrm{Gln}}$, and tRNA $\mathrm{Glu}$ and that the phenotypes of Elongator mutants are caused by inefficient decoding of the respective cognate codons. This notion is further supported by the observation

that the inactivation of the Ncs2/Ncs6 complex, which catalyzes the formation of the $\mathrm{s}^{2}$ group, induces essentially the same phenotypes that are also suppressed by increased expression of the tRNA $\mathrm{LUU}_{\mathrm{UUU}}^{\mathrm{Ly}}, \mathrm{tRNA}_{\mathrm{UUG}}^{\mathrm{Gln}}$, and tRNA $\mathrm{UUC}_{\mathrm{UUC}}^{\mathrm{Glu}}$ combinations (Björk et al. 2007; Chen et al. 2011; Esberg et al. 2006; Huang et al. 2008; Leidel et al. 2009; Nakai et al. 2008; Noma et al. 2009). Moreover, ribosome profiling experiments have shown that the lack of wobble $\mathrm{mcm}^{5}$ / $\mathrm{ncm}^{5}$ and/or s $\mathrm{s}^{2}$ groups leads to an accumulation of ribosomes with AAA, CAA, and GAA codons in their A-site (Chou et al. 2017; Nedialkova and Leidel 2015; Zinshteyn and Gilbert 2013). The mechanism by which the inefficient decoding of these codons induces the phenotypes are not well understood. One model suggests that the phenotypes may be caused by reduced expression of factors encoded from mRNAs enriched in AAA, CAA, and/or GAA codons (Bauer et al. 2012; Chen et al. 2011; Fernandez-Vazquez et al. 2013; Rezgui et al. 2013). In this model, the slower decoding of the mRNA leads to reduced protein abundance by a mechanism that may involve elevated levels of frameshifting or inhibition of translation initiation through ribosome queuing. Another model suggests that the phenotypes may be caused by the proteotoxic stress that arises from defects in co-translational protein folding and the consequent accumulation of protein aggregates (Nedialkova and Leidel 2015). As the proteins that show increased aggregation in strains lacking the $\mathrm{mcm} / \mathrm{ncm}^{5}$ and $\mathrm{s}^{2}$ groups are not encoded by mRNAs enriched in AAA, CAA, and/or GAA codons (Nedialkova and Leidel 2015), it remains unclear if the protein aggregation is a direct or indirect consequence of the inefficient decoding of these codons.

The recent finding that the phenotypes of Elongator-deficient cells are influenced by the allelic variant at the SSDI locus provides additional information into the pleiotropic effects of Elongator (Xu et al. 2019). Several wild-type laboratory $S$. cerevisiae strains harbor a nonsense mutation in the $S S D 1$ gene, which encodes an mRNA-binding protein that associates with a subset of mRNAs and regulates their stability, translation, and/or localization (Hogan et al. 2008; Jansen et al. 2009; Jorgensen et al. 2002; Kurischko et al. 2011; Ohyama et al. 2010; Sutton et al. 1991; Uesono et al. 1997; Wanless et al. 2014). The notion that the SSDI locus influences the phenotypes of Elongator mutants was inferred from the observation that the temperature sensitivity (Ts) of cells deleted for ELP3, which encodes an Elongator subunit, is significantly stronger in the W303 than in the related S288C genetic background (Xu et al. 2019). Strains in the W303 genetic background contain the nonsense $s s d l-d 2$ allele whereas those in S288C harbor an SSD1 allele that encodes the full-length functional protein (Jorgensen et al. 2002; Sutton et al. 1991). Analyses of congenic $s s d l-d 2$ elp $3 \Delta$ and SSD1 elp $3 \Delta$ strains, in both genetic backgrounds, showed that the $s s d 1-d 2$ allele not only aggravates the Ts 
phenotype of elp $3 \Delta$ mutants but also the growth defects induced by various stress-inducing agents (Xu et al. 2019). In these assays, the effect of the $s s d l-d 2$ mutation is comparable to an ssdl $1 \Delta$ allele. Further, the telomeric gene silencing and histone $\mathrm{H} 3$ acetylation defects of W303-derived Elongator mutants were found to be dependent on the $s s d l$ $d 2$ allele, i.e., the phenotypes are suppressed by the introduction of the SSD1 gene.

The SSDI gene has been genetically implicated in a diverse range of cellular pathways and processes, including cell morphogenesis, cell wall integrity, cellular aging, virulence, several signal transduction pathways, protein homeostasis, and transcription by RNA polymerase I, II, and III (Jorgensen et al. 2002; Kaeberlein et al. 2004; Kaeberlein and Guarente 2002; Stettler et al. 1993; Wheeler et al. 2003; Wilson et al. 1991). A likely explanation to the large number of genetic interactions is the function of Ssd1 in post-transcriptional gene regulation. For the Ssd1-associated mRNAs that encode factors involved in cell wall biosynthesis, Ssd1 is thought, depending on its phosphorylation status, to promote either translational repression or polarized localization (Jansen et al. 2009; Kurischko et al. 2011; Wanless et al. 2014). Moreover, the inactivation of SSD1 alters the abundance and stability of many mRNAs and this effect is not restricted to Ssd1-associated transcripts (Jansen et al. 2009; Li et al. 2009a). The precise mechanisms by which the allele at the SSD1 locus influences the phenotypes of Elongator mutants are not known, but they may involve both direct and indirect effects of Ssd1's function in messenger ribonucleoprotein complexes. The $s s d 1-d 2$ allele does not influence the formation of the $\mathrm{mcm} / \mathrm{ncm}^{5}$ groups and analyses of the ssd1-d2 elp3A and SSD1 elp $3 \Delta$ strains revealed no apparent difference in tRNA levels or the abundance of other modified nucleosides (Xu et al. 2019). Further, +1 frameshifting assays indicated that the A-site selection rate at the AAA codon is comparable in ssdl-d2 elp $3 \Delta$ and SSD1 elp3A strains. While these observations suggest that the $s s d 1-d 2$ allele does not influence the abundance or functionality of the hypomodified tRNAs, it remains possible that the lack of Ssd1 may affect tRNA function under stress conditions. However, the two phenotypes that are dependent on the $s s d 1-d 2$ allele, the histone $\mathrm{H} 3$ acetylation and telomeric gene silencing defect, are detected under standard growth conditions, indicating that at least these phenotypes are not caused by a synergistic effect on tRNA function. The telomeric gene silencing defect in Elongator mutants is thought to be caused by reduced levels of the Sir4 protein, which is involved in the assembly of silent chromatin (Chen et al. 2011). The SIR4 open reading frame is enriched in AAA codons and the telomeric gene silencing defect is suppressed by increased expression of tRNA $\mathrm{UUU}_{\mathrm{UU}}^{\mathrm{Lys}}$ (Chen et al.
2011). Further, the overexpression of tRNA $\mathrm{UUU}_{\mathrm{UU}}^{\mathrm{Lys}}$ restores Sir4 levels without significantly influencing the mRNA levels (Chen et al. 2011). Even though these observations imply that the decreased silencing at telomeres is caused by reduced Sir4 levels, it is not known if the reduction is large enough to cause the phenotype and if it is a direct consequence of inefficient decoding of the SIR4 mRNA. Nevertheless, the finding that the telomeric gene silencing defect is dependent on the $s s d l-d 2$ allele shows that the lack of the $\mathrm{mcm}^{5} / \mathrm{ncm}^{5}$ groups is not sufficient to induce the phenotype (Xu et al. 2019). Additional experiments are needed to investigate if the levels of Sir4 are modulated by the allele at the SSD1 locus.

The effect of the $S S D 1$ locus also partially explained why an elp $3 \Delta$ ncs $2 \Delta$ double mutant, which lacks both the $\mathrm{mcm}^{5}$ / $\mathrm{ncm}^{5}$ and $\mathrm{s}^{2}$ groups, is nonviable in the W303 but not in the S288C genetic background (Björk et al. 2007; Klassen et al. 2015; Nedialkova and Leidel 2015; Xu et al. 2019). An ssd1$d 2$ elp $3 \Delta$ ncs $2 \Delta$ strain is, however, viable but very slowgrowing in the S288C background, indicating the growth phenotype is influenced by additional genetic factors (Xu et al. 2019). Consistent with the finding that $\mathrm{Ssd} 1$ promotes Hsp104-mediated protein disaggregation (Mir et al. 2009), the levels of aggregated proteins were found to be higher in $s s d 1-d 2$ elp $3 \Delta$ ncs $2 \Delta$ than in SSD1 elp $3 \Delta n c s 2 \Delta$ cells (Xu et al. 2019). Although these observations indicate that the slow growth of the $s s d 1-d 2$ elp $3 \Delta n c s 2 \Delta$ strain may be caused by the accumulation of protein aggregates, it is not known if the aggregation is the cause or the consequence of the growth defect.

The presence of the nonsense $s s d l-d 2$ allele sensitizes yeast cells to the translational defects induced by the lack of Elongator-dependent tRNA modifications. Future work is needed to define the mechanisms by which SSD1 modulates the phenotypes of Elongator-deficient cells. It also remains to be determined if the phenotypes of Elongator mutants in other organisms are modulated by polymorphisms in genes for mRNA-binding proteins.

Acknowledgements Open access funding provided by Umeå University. The work in the authors' laboratories was supported by grants from the Magnus Bergvall Foundation (2017-02098 to MJOJ); Ake Wiberg Foundation (M14-0207 to MJOJ); Swedish Research Council (621-2016-03949 to ASB), and Karin and Harald Silvanders Foundation/Insamlingsstiftelsen Umeå universitet (FS 2.1.6-1870-16 to ASB).

Open Access This article is distributed under the terms of the Creative Commons Attribution 4.0 International License (http://creativeco mmons.org/licenses/by/4.0/), which permits unrestricted use, distribution, and reproduction in any medium, provided you give appropriate credit to the original author(s) and the source, provide a link to the Creative Commons license, and indicate if changes were made. 


\section{References}

Agris PF, Narendran A, Sarachan K, Vare VYP, Eruysal E (2017) The importance of being modified: the role of RNA modifications in translational fidelity. Enzymes 41:1-50. https://doi.org/10.1016/ bs.enz.2017.03.005

Bauer F et al (2012) Translational control of cell division by Elongator. Cell Rep 1:424-433. https://doi.org/10.1016/j.celrep.2012.04.001

Björk GR, Hagervall TG (2014) Transfer RNA modification: presence, synthesis, and function. EcoSal Plus. https://doi.org/10.1128/ ecosalplus.ESP-0007-2013

Björk GR, Huang B, Persson OP, Byström AS (2007) A conserved modified wobble nucleoside $(\mathrm{mcm} 5 \mathrm{~s} 2 \mathrm{U})$ in lysyl-tRNA is required for viability in yeast. RNA 13:1245-1255. https://doi.org/10.1261/ rna.558707

Chen C, Huang B, Eliasson M, Ryden P, Byström AS (2011) Elongator complex influences telomeric gene silencing and DNA damage response by its role in wobble uridine tRNA modification. PLoS Genet 7:e1002258. https://doi.org/10.1371/journal.pgen.1002258

Chou HJ, Donnard E, Gustafsson HT, Garber M, Rando OJ (2017) Transcriptome-wide analysis of roles for tRNA modifications in translational regulation. Mol Cell 68(978-992):e974. https://doi. org/10.1016/j.molcel.2017.11.002

Dauden MI et al (2017) Architecture of the yeast Elongator complex. EMBO Rep 18:264-279. https://doi.org/10.15252/embr.20164 3353

Dauden MI, Jaciuk M, Muller CW, Glatt S (2018) Structural asymmetry in the eukaryotic Elongator complex. FEBS Lett 592:502-515. https://doi.org/10.1002/1873-3468.12865

Esberg A, Huang B, Johansson MJ, Byström AS (2006) Elevated levels of two tRNA species bypass the requirement for elongator complex in transcription and exocytosis. Mol Cell 24:139-148. https ://doi.org/10.1016/j.molcel.2006.07.031

Fernandez-Vazquez $\mathbf{J}$ et al (2013) Modification of tRNA(Lys) UUU by elongator is essential for efficient translation of stress mRNAs. PLoS Genet 9:e1003647. https://doi.org/10.1371/journ al.pgen. 1003647

Frohloff F, Fichtner L, Jablonowski D, Breunig KD, Schaffrath R (2001) Saccharomyces cerevisiae Elongator mutations confer resistance to the Kluyveromyces lactis zymocin. EMBO J 20:1993-2003. https://doi.org/10.1093/emboj/20.8.1993

Hogan DJ, Riordan DP, Gerber AP, Herschlag D, Brown PO (2008) Diverse RNA-binding proteins interact with functionally related sets of RNAs, suggesting an extensive regulatory system. PLoS Biol 6:e255. https://doi.org/10.1371/journal.pbio.0060255

Huang B, Johansson MJO, Byström AS (2005) An early step in wobble uridine tRNA modification requires the Elongator complex. RNA 11:424-436. https://doi.org/10.1261/rna.7247705

Huang B, Lu J, Byström AS (2008) A genome-wide screen identifies genes required for formation of the wobble nucleoside 5-methoxycarbonylmethyl-2-thiouridine in Saccharomyces cerevisiae. RNA 14:2183-2194. https://doi.org/10.1261/rna.1184108

Jansen JM, Wanless AG, Seidel CW, Weiss EL (2009) Cbk1 regulation of the RNA-binding protein Ssd1 integrates cell fate with translational control. Curr Biol 19:2114-2120. https://doi.org/10.1016/j. cub.2009.10.071

Johansson MJO, Esberg A, Huang B, Björk GR, Byström AS (2008) Eukaryotic wobble uridine modifications promote a functionally redundant decoding system. Mol Cell Biol 28:3301-3312. https ://doi.org/10.1128/MCB.01542-07

Johansson MJO, Xu F, Byström AS (2018) Elongator-a tRNA modifying complex that promotes efficient translational decoding. Biochim Biophys Acta Gene Regul Mech 1861:401-408. https://doi. org/10.1016/j.bbagrm.2017.11.006
Jorgensen P, Nelson B, Robinson MD, Chen Y, Andrews B, Tyers M, Boone $C$ (2002) High-resolution genetic mapping with ordered arrays of Saccharomyces cerevisiae deletion mutants. Genetics 162:1091-1099

Kaeberlein M, Guarente L (2002) Saccharomyces cerevisiae MPT5 and SSD1 function in parallel pathways to promote cell wall integrity. Genetics 160:83-95

Kaeberlein M, Andalis AA, Liszt GB, Fink GR, Guarente L (2004) Saccharomyces cerevisiae SSD1-V confers longevity by a Sir2pindependent mechanism. Genetics 166:1661-1672

Karlsborn T, Tukenmez H, Mahmud AK, Xu F, Xu H, Byström AS (2014) Elongator, a conserved complex required for wobble uridine modifications in eukaryotes. RNA Biol 11:1519-1528. https ://doi.org/10.4161/15476286.2014.992276

Klassen R, Grunewald P, Thuring KL, Eichler C, Helm M, Schaffrath $\mathrm{R}$ (2015) Loss of anticodon wobble uridine modifications affects tRNA(Lys) function and protein levels in Saccharomyces cerevisiae. PLoS One 10:e0119261. https://doi.org/10.1371/journ al.pone. 0119261

Kolaj-Robin O, Seraphin B (2017) Structures and activities of the Elongator complex and its cofactors. Enzymes 41:117-149. https://doi. org/10.1016/bs.enz.2017.03.001

Kurischko C, Kim HK, Kuravi VK, Pratzka J, Luca FC (2011) The yeast Cbk1 kinase regulates mRNA localization via the mRNAbinding protein Ssd1. J Cell Biol 192:583-598. https://doi. org/10.1083/jcb.201011061

Leidel S et al (2009) Ubiquitin-related modifier Urm1 acts as a sulphur carrier in thiolation of eukaryotic transfer RNA. Nature 458:228 232. https://doi.org/10.1038/nature07643

Li L, Lu Y, Qin LX, Bar-Joseph Z, Werner-Washburne M, Breeden LL (2009a) Budding yeast SSD1-V regulates transcript levels of many longevity genes and extends chronological life span in purified quiescent cells. Mol Biol Cell 20:3851-3864. https://doi. org/10.1091/mbc.E09-04-0347

Li Q, Fazly AM, Zhou H, Huang S, Zhang Z, Stillman B (2009b) The elongator complex interacts with PCNA and modulates transcriptional silencing and sensitivity to DNA damage agents. PLoS Genet 5:e1000684. https://doi.org/10.1371/journal.pgen.1000684

Lim VI (1994) Analysis of action of wobble nucleoside modifications on codon-anticodon pairing within the ribosome. J Mol Biol 240:8-19. https://doi.org/10.1006/jmbi.1994.1413

Machnicka MA, Olchowik A, Grosjean H, Bujnicki JM (2014) Distribution and frequencies of post-transcriptional modifications in tRNAs. RNA Biol 11:1619-1629. https://doi.org/10.4161/15476 286.2014.992273

Mir SS, Fiedler D, Cashikar AG (2009) Ssd1 is required for thermotolerance and Hsp104-mediated protein disaggregation in Saccharomyces cerevisiae. Mol Cell Biol 29:187-200. https://doi. org/10.1128/MCB.02271-07

Nakai Y, Nakai M, Hayashi H (2008) Thio-modification of yeast cytosolic tRNA requires a ubiquitin-related system that resembles bacterial sulfur transfer systems. J Biol Chem 283:27469-27476. https://doi.org/10.1074/jbc.M804043200

Nedialkova DD, Leidel SA (2015) Optimization of codon translation rates via tRNA modifications maintains proteome integrity. Cell 161:1606-1618. https://doi.org/10.1016/j.cell.2015.05.022

Noma A, Sakaguchi Y, Suzuki T (2009) Mechanistic characterization of the sulfur-relay system for eukaryotic 2-thiouridine biogenesis at tRNA wobble positions. Nucleic Acids Res 37:1335-1352. https://doi.org/10.1093/nar/gkn1023

Ohyama Y, Kasahara K, Kokubo T (2010) Saccharomyces cerevisiae Ssd1p promotes CLN2 expression by binding to the 5'-untranslated region of CLN2 mRNA. Genes Cells 15:1169-1188. https ://doi.org/10.1111/j.1365-2443.2010.01452.x 
Otero G et al (1999) Elongator, a multisubunit component of a novel RNA polymerase II holoenzyme for transcriptional elongation. Mol Cell 3:109-118

Rahl PB, Chen CZ, Collins RN (2005) Elp1p, the yeast homolog of the FD disease syndrome protein, negatively regulates exocytosis independently of transcriptional elongation. Mol Cell 17:841-853. https://doi.org/10.1016/j.molcel.2005.02.018

Rezgui VA et al (2013) tRNA tKUUU, tQUUG, and tEUUC wobble position modifications fine-tune protein translation by promoting ribosome A-site binding. Proc Natl Acad Sci USA 110:1228912294. https://doi.org/10.1073/pnas. 1300781110

Setiaputra DT et al (2017) Molecular architecture of the yeast Elongator complex reveals an unexpected asymmetric subunit arrangement. EMBO Rep 18:280-291. https://doi.org/10.15252 /embr. 201642548

Stettler S, Chiannilkulchai N, Hermann-Le Denmat S, Lalo D, Lacroute F, Sentenac A, Thuriaux P (1993) A general suppressor of RNA polymerase I, II and III mutations in Saccharomyces cerevisiae. Mol Gen Genet 239:169-176

Sutton A, Immanuel D, Arndt KT (1991) The SIT4 protein phosphatase functions in late $\mathrm{G} 1$ for progression into $\mathrm{S}$ phase. Mol Cell Biol 11:2133-2148. https://doi.org/10.1128/mcb.11.4.2133

Tigano M, Ruotolo R, Dallabona C, Fontanesi F, Barrientos A, Donnini C, Ottonello S (2015) Elongator-dependent modification of cytoplasmic tRNALysUUU is required for mitochondrial function under stress conditions. Nucleic Acids Res 43:8368-8380. https ://doi.org/10.1093/nar/gkv765

Uesono Y, Toh-e A, Kikuchi Y (1997) Ssd1p of Saccharomyces cerevisiae associates with RNA. J Biol Chem 272:16103-16109

Wanless AG, Lin Y, Weiss EL (2014) Cell morphogenesis proteins are translationally controlled through UTRs by the Ndr/LATS target Ssd1. PLoS One 9:e85212. https://doi.org/10.1371/journ al.pone. 0085212
Wheeler RT, Kupiec M, Magnelli P, Abeijon C, Fink GR (2003) A Saccharomyces cerevisiae mutant with increased virulence. Proc Natl Acad Sci USA 100:2766-2770. https://doi.org/10.1073/ pnas.0437995100

Wilson RB, Brenner AA, White TB, Engler MJ, Gaughran JP, Tatchell K (1991) The Saccharomyces cerevisiae SRK1 gene, a suppressor of bcy1 and ins1, may be involved in protein phosphatase function. Mol Cell Biol 11:3369-3373

Winkler GS, Petrakis TG, Ethelberg S, Tokunaga M, Erdjument-Bromage H, Tempst P, Svejstrup JQ (2001) RNA polymerase II elongator holoenzyme is composed of two discrete subcomplexes. $\mathbf{J}$ Biol Chem 276:32743-32749. https://doi.org/10.1074/jbc.M1053 03200

Winkler GS, Kristjuhan A, Erdjument-Bromage H, Tempst P, Svejstrup JQ (2002) Elongator is a histone H3 and H4 acetyltransferase important for normal histone acetylation levels in vivo. Proc Natl Acad Sci USA 99:3517-3522. https://doi.org/10.1073/pnas.02204 2899

Xu F, Byström AS, Johansson MJO (2019) SSD1 suppresses phenotypes induced by the lack of Elongator-dependent tRNA modifications. PLoS Genet 15:e1008117. https://doi.org/10.1371/journ al.pgen. 1008117

Zinshteyn B, Gilbert WV (2013) Loss of a conserved tRNA anticodon modification perturbs cellular signaling. PLoS Genet 9:e1003675. https://doi.org/10.1371/journal.pgen.1003675

Publisher's Note Springer Nature remains neutral with regard to jurisdictional claims in published maps and institutional affiliations. 